\title{
Correction to: Monitored Sewage Sludge Application Improves Soil Quality, Enhances Plant Growth, and Provides Evidence for Metal Remediation by Sorghum bicolor L.
}

\author{
Ebrahem M. Eid ${ }^{1,2} \cdot$ Kamal H. Shaltout $^{3}$ - Saad A. M. Alamri ${ }^{1}$. Sulaiman A. Alrumman ${ }^{1} \cdot$ Ahmed A. Hussain $^{1}$. \\ Nasser Sewelam ${ }^{3}$ (1) . Gehad A. Ragab ${ }^{3}$
}

Published online: 6 July 2021

(c) Sociedad Chilena de la Ciencia del Suelo 2021

\section{Correction to: J Soil Sci Plant Nutr} https://doi.org/10.1007/s42729-021-00524-x

There were two errors in this article as originally published:

(1) A period was missing from the " $\mathrm{L}$ " in the article title

(2) The color bar missing from the graphic for Fig. 3.

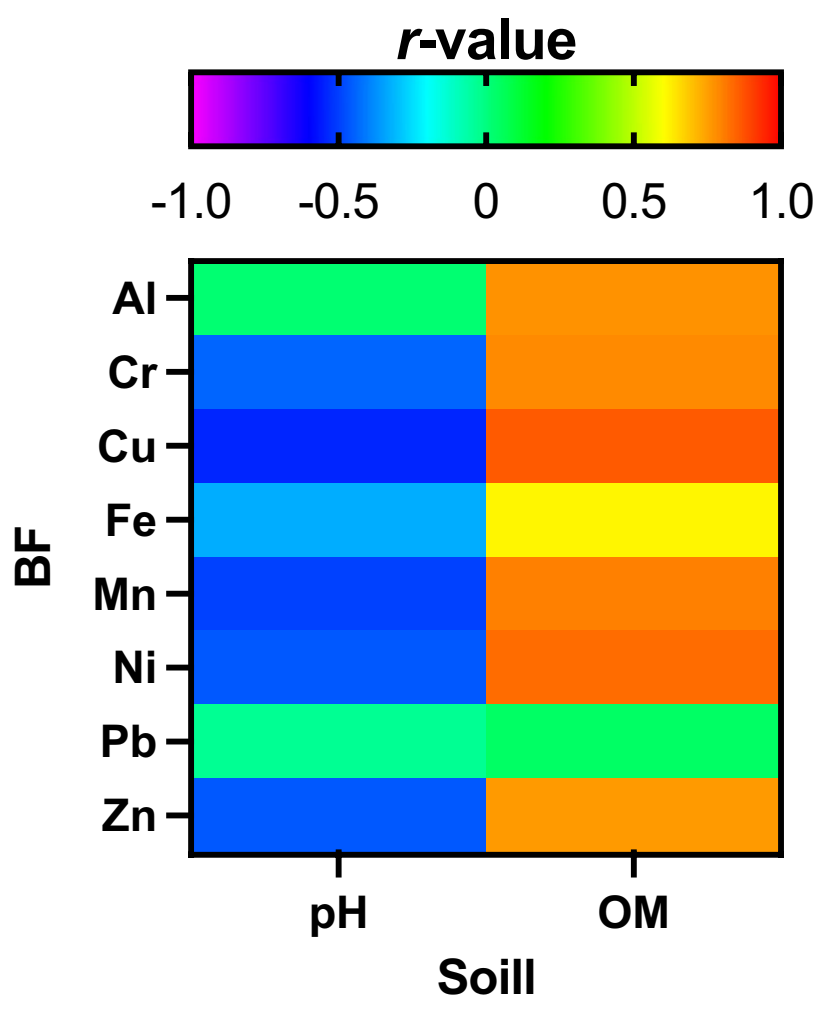

The original article can be found online at https://doi.org/10.1007/ s42729-021-00524-x.

Nasser Sewelam

sewelam@science.tanta.edu.eg

The original article has been updated

1 Biology Department, College of Science, King Khalid University, Abha 61321, Saudi Arabia

2 Botany Department, Faculty of Science, Kafrelsheikh University, Kafr El-Sheikh 33516, Egypt

Publisher's Note Springer Nature remains neutral with regard to jurisdictional claims in published maps and institutional affiliations.

3 Botany Department, Faculty of Science, Tanta University, Tanta 31527, Egypt 